\section{The Effect of Feeling Stereotyped on Social Power and Inhibition}

\author{
Jonathan E. Cook', Holly Arrow', and Bertram F. Malle'
}

Personality and Social

Psychology Bulletin $37(2) 165-180$

(c) 2011 by the Society for Personality and Social Psychology, Inc

Reprints and permission:

sagepub.com/journalsPermissions.nav DOI: $10.1177 / 0146167210390389$

http://pspb.sagepub.com

@SAGE

\begin{abstract}
An experience sampling study examined the degree to which feeling stereotyped predicts feelings of low power and inhibition among stigmatized and nonstigmatized individuals. For 7 days, participants with a concealable (gay and lesbian), a visible (African American), or no identifiable stigma recorded feelings of being stereotyped, of powerlessness, and of inhibition immediately following social interactions. For members of all three groups, feeling stereotyped was associated with more inhibition, and this relation was partially mediated by feeling low in power. Although stigmatized participants reported feeling stereotyped more often than nonstigmatized participants, they reacted less strongly to the experience, consistent with the presence of buffering mechanisms developed by those living with stigma. African Americans appeared to buffer the impact of feeling stereotyped more effectively than gay and lesbian participants, an effect that was partly attributable to African Americans' higher identity centrality.
\end{abstract}

\title{
Keywords
}

stereotypes, inhibition, power, stigma

Received April 23, 2009; revision accepted September 6, 2010

When people feel stereotyped because of a social identity, the resulting identity threat (Steele, Spencer, \& Aronson, 2002) can generate negative affect (Mendoza-Denton, Downey, Purdie, Davis, \& Pietrzak, 2002; Steele et al., 2002), cognitive vigilance (Pinel, 1999; Steele et al., 2002), and instrumental social behavior (Shelton, Richeson, \& Salvatore, 2005). These same outcomes characterize the inhibition system (Gray, 1994; Keltner, Gruenfeld, \& Anderson, 2003). If, as Keltner et al. (2003) propose, one cause of inhibition is powerlessness, then inhibitory responses to feeling stereotyped may result in part from a sense of powerlessness that feeling stereotyped evokes. Because stereotypes are based on group categorization, when people perceive that they are being viewed through the deindividuating lens of a stereotype - regardless of its valence (Fiske, Xu, Cuddy, \& Glick, 1999) — they are likely to feel less control over their immediate outcomes.

The present study tests the possibility that a reduced sense of social power mediates the inhibitory effects of feeling stereotyped. Although others have also suggested an association between feeling stereotyped and powerlessness (see, e.g., Hebl \& Dovidio, 2005; Keltner et al., 2003), to our knowledge this association has never been examined empirically. We test the relation between feeling stereotyped, subjective power, and inhibitory responses among three groups who differ in stigma status: White gays and lesbians, heterosexual African Americans, and heterosexual Whites with no identifiable stigmas. Because stereotypes exist for virtually every group, the relations among these variables should apply broadly, but members of stigmatized groups should feel stereotyped more often (Adams, Tormala, \& O’Brien, 2006).

If belonging to a stigmatized group increases the frequency of feeling stereotyped, does it follow that members of such groups will feel, on average, more powerless and inhibited than those with no identifiable stigma? Not necessarily. Research on the resilience of stigmatized groups (Inzlicht, Aronson, Good, \& McKay, 2006) and their well-developed coping strategies (Crocker \& Major, 1989) suggests that people who are frequently stereotyped may adapt to the experience by buffering their inhibitory responses.

We tested both the power mediation model and the buffering hypothesis using data on momentary assessments of stereotyping, power, and inhibition in everyday social interactions, collected using an experience sampling design. Beyond the general importance of field research for understanding and describing naturally occurring psychological processes

'University of Oregon, Eugene, OR, USA

\section{Corresponding Author:}

Jonathan E. Cook, Department of Psychology, Columbia University, 406 Schermerhorn Hall, I 90 Amsterdam Avenue, MC 550I,

New York, NY 10027

Email: jecook@columbia.edu 
(Cialdini, 2009), this design provided a wealth of withinpersons data that allowed us to assess how participants' thoughts and feelings varied across social interactions as a function of subjective power and feeling stereotyped. Capturing participants' thoughts and feelings at the time of their social interactions minimizes the problems of motivated processing that can contaminate retrospective reporting (Reis \& Gable, 2000).

\section{Power and Inhibition}

Drawing on the work of French and Raven (1959; Raven, 1993), we define power broadly as a person's potential to influence others, similar to Keltner et al.'s (2003) “relative capacity to modify others' states" (p. 265). Like other researchers (e.g., Galinsky, Gruenfeld, \& Magee, 2003; Keltner et al., 2003), we view power as a psychological state that can be felt even in the absence of observable indicators of a power structure. The approach-inhibition theory (Keltner et al., 2003) proposes that low power activates an inhibition system characterized by negative emotion, cognitive vigilance, and constrained behavior. High power activates an approach system characterized by attention to rewards, positive emotion, automatic cognition, and disinhibited behavior.

Many aspects of the proposed relation between high power and approach have been supported experimentally using either a structural manipulation of power (i.e., control over resources vs. dependency on others for resources) or a priming manipulation of power (e.g., writing about a time of feeling powerful or powerless). Using these approaches, researchers have provided convincing evidence that high power motivates disinhibited behavior and attention to rewards (Anderson \& Berdahl, 2002; Anderson \& Galinsky, 2006; Galinsky et al., 2003; Guinote, 2007b; Magee, Galinsky, \& Gruenfeld, 2007; Smith \& Bargh, 2008) and preliminary evidence that elevated power leads to positive emotion (Berdahl \& Martorana, 2006). One challenge that has emerged in testing the approachinhibition theory, however, is the dissimilitude between the effects of high- and low-power manipulations. Most studies that include control groups (Anderson \& Galinsky, 2006; Galinsky et al., 2003; Smith \& Bargh, 2008) or compare data from low-power participants with preexisting data on typical functioning (Guinote, 2007a) have found little to distinguish participants in the "low-power" condition from controls on relevant outcomes (though see Smith, Jostmann, Galinsky, \& van Dijjk, 2008, for a recent exception).

The difficulty in demonstrating the impact of low power on inhibition may be at least partly due to methodological challenges. Because need for control is a core social motive (Fiske, 2004), participants may welcome high-power manipulations but resist low-power manipulations in laboratory settings (Berdahl \& Martorana, 2006). Meaningful social interactions in everyday life may allow for a contextually valid test of the relation between low social power and inhibition by providing a broader sample of experiences that are more immediately relevant to participants' lives and naturally vary more in social power. Hence, we expected our study to contribute useful evidence for evaluating an aspect of the approach-inhibition theory that has so far garnered limited support.

\section{The Buffering Effect of Experience With Stigma}

Feeling stereotyped is not unique to members of stigmatized groups (Vorauer, Main, \& O’Connell, 1998), but they do feel stereotyped more frequently than people without an identifiable stigma (Adams et al., 2006). In fact, stigma can be defined as a culturally devalued distinction that results in the formation of negative inferences, often leading to prejudice and discrimination (Dovidio, Major, \& Crocker, 2000). One response to a frequently recurring threat, whether environmental or social, is to deploy strategies to neutralize the threat. In fact, a wellestablished finding in the study of stigma is that members of stigmatized groups develop coping mechanisms that mitigate many of the expected negative psychological effects of a devalued identity (Crocker \& Major, 1989; Major, 2006; Miller, 2006). The protective effects of coping mechanisms on self-esteem, for example, help explain why the dispositional detriments to self-esteem once envisioned in stigmatized groups failed to materialize (e.g., Crocker \& Major, 1989). These self-protective strategies may also help buffer against inhibitory reactions to feeling stereotyped. In the current study, we include participants with and without stigmatized identities, allowing us to test whether members of stigmatized groups do indeed have a less markedly negative response to feeling stereotyped than people without stigmas, who should feel stereotyped more rarely.

\section{The Impact of Stigma Type}

The study included members of two distinct stigmatized groups - African Americans and gay or lesbian individuals - to help address the gap in knowledge about whether and how people with different kinds of stigmas differ in their psychological responses to feeling stereotyped. For example, people with visible stigmas (such as African Americans) are thought to incorporate their stigma into self-identity more centrally than those with potentially concealable stigmas (such as being gay), largely because the stigma is an unavoidable feature of any social interaction (Quinn, 2006).

The consequences of greater identity centrality are somewhat controversial. Although some researchers suggest that centrality provides a psychological buffer that increases with discrimination (e.g., Bourguignon, Seron, Yzerbyt, \& Herman, 2006; Branscombe, Schmitt, \& Harvey, 1999), others suggest that centrality is more like a lens that amplifies perceptions of discrimination (e.g., Eccleston \& Major, 2006; Major, Quinton, \& Schmader, 2003). Interestingly, these perspectives may 
actually be complementary rather than incompatible. Sellers and Shelton (2003) have noted that even if centrality increases perceptions of discrimination, "what could make people appear to be vigilant for discrimination may also buffer them from the adverse consequences" (p. 1087). Given the generally positive relation between identity centrality and well-being (e.g., Bourguignon et al., 2006; Eccleston \& Major, 2006; Sellers \& Shelton, 2003; but see McCoy \& Major, 2003, for an exception), lower identity centrality among people with concealable stigmas may increase vulnerability to the negative consequences of feeling stereotyped compared to those with a visible stigma.

Of course, the visibility or concealability of stigma is only one of many differences between the experiences of African Americans and White gays and lesbians in the United States. Very little research has empirically addressed the issue of stigma visibility (Quinn, 2006), and research rarely includes people with both visible and concealable stigmas in the same study. Hence, our investigation of similarities and differences in responses among the two stigmatized groups is exploratory in nature.

\section{Overview of Study and Hypotheses}

Our study was designed to test hypotheses about the relation between feeling stereotyped, social power, and inhibition in the natural social interactions of stigmatized and nonstigmatized participants. We also wanted to explore possible differences between stigma type (visible or concealable) in any buffering effects.

The stereotype hypothesis predicts that feeling stereotyped will be associated with both increased inhibition and decreased feelings of power.

The power mediation hypothesis predicts that reduced social power should mediate the relation between feeling stereotyped and feeling inhibited.

The stigma buffer hypothesis predicts that stigmatized participants should have a less strongly negative response to feeling stereotyped than nonstigmatized participants.

\section{Method}

Participants were initially recruited to complete a set of online questionnaires that were used to gather background information and provide an eligibility screen for the experience sampling study. The main study used an event-contingent experience sampling design, with both between- and within-participants components, with events defined as social interactions lasting at least $3 \mathrm{~min}$. Participants were asked to answer a set of questions immediately after each social interaction using a Dell Axim X51 personal digital assistant (PDA). The PDAs also made periodic, voice-activated audio recordings of participant interactions. ${ }^{1}$ Whenever audio samples were collected, the PDA also prompted participants to complete the social interaction survey. Thus, to some extent voice activation added a signal contingency to data collection. Before, during, and immediately after the study, participants completed supplemental questionnaires online.

\section{Participants}

Sixty-nine eligible participants completed training for the experience sampling study. Of these, 2 participants did not collect any data, 1 provided data that appeared fabricated, ${ }^{2}$ and 2 more were dropped from the study for not complying with study protocols. The final number of participants was 64 , ranging in age from 18 to 44 with a mean of 23.98 $(S D=6.10)$.

Because of difficulties recruiting African American men, the gender composition of the three stigma groups differed in the final sample, $\chi^{2}(2, N=64)=6.88, p<.05$. There were 10 females in the no-stigma and gay and lesbian groups and 17 women in the African American group. There were 12 males in the no-stigma group and 11 in the gay and lesbian group, but only 4 in the African American group.

\section{Procedure}

University and community participants were recruited using flyers and online announcements on social networking sites that directed interested people to an online screening questionnaire. Responses to the screening questionnaire were used to select native English speakers who belonged to one of three groups: European American heterosexuals with no identifiable stigmas (i.e., nonstigma group), European Americans who were gay or lesbian, and African Americans who were heterosexual. Gay and lesbian participants remained eligible if they had other concealable stigmas (e.g., an eating disorder) but were generally excluded if they had a visible stigma (e.g., obesity). Because the construct of race is a visible characteristic, African American participants remained eligible if they had other stigmas. The stigma groups were selected as prototypical examples of visible (African American) and concealable (gay and lesbian) stigmas that expose people to a high probability of being stereotyped in the United States.

Eligible participants were invited to attend an hour-long training and orientation session for the experience sampling study, which they were told required "commitment and motivation" and an interest in "helping to advance science." They were reminded that the study would last a week and were provided a cash stipend of $\$ 50$ as well as a personal profile based on study responses. People who did not respond were contacted one or two additional times before being removed from the list of potential participants.

When participants arrived for training, they received a brief overview of the study, completed informed consent documents, and were given a detailed explanation of study procedures. At all times, participants were treated respectfully and with 
gratitude, and the importance of their role as research collaborators was emphasized (Christensen, Barrett, Bliss-Moreau, Lebo, \& Kaschub, 2003; Reis \& Gable, 2000). Participants were instructed to manually initiate the experience sampling survey after each social interaction, which was defined as "live" communication (i.e., in person, on the phone, or through a real-time instant message program), with adults, lasting at least $3 \mathrm{~min}$. A PDA emulator was projected onto a screen to demonstrate the experience sampling questionnaire, and participants were guided through the various options with detailed instructions. Participants were asked to complete at least 10 experience sampling surveys each day from a broad but representative sample of their interactions ${ }^{3}$ and were asked to complete a brief End-of-Day (EOD) Questionnaire each evening.

Participants received phone and e-mail information for a contact person and were encouraged to report any thoughts, concerns, or technological problems that might arise. Over the week, the experimenters contacted participants by e-mail or telephone at regular intervals to ensure compliance and maintain motivation (Christensen et al., 2003; Reis \& Gable, 2000). Communication with participants who fell behind on the EOD Questionnaire or who had problems with equipment was more frequent, often involving phone calls or meeting in person to exchange equipment or troubleshoot. At the end of the study, participants returned to drop off the equipment, complete a Final Experience Questionnaire, and receive payment.

\section{Materials}

\section{Screening Questionnaire}

Demographic data. Demographic questions included age, gender, ethnicity, and sexual orientation. Participants who indicated an ethnicity other than Caucasian or African American were excluded from further participation, as were participants who were not native English speakers and those who reported a sexual orientation other than "straight" or "gay/lesbian."

Stigma assessment. To ensure that the nonstigmatized sample was free from several common stigmas, participants indicated whether they had symptoms of an eating disorder, were more than $60 \mathrm{lb}$ overweight, were being treated for a mental disorder, had a physical disability, or had some other characteristics that made social interactions unusual for them.

Identity centrality. Identity centrality is a stable trait construct, referring to the degree to which people view a group membership as a core aspect of identity. African American and gay and lesbian participants completed the centrality scale of the Multidimensional Inventory of Black Identity (MIBI; Sellers, Rowley, Chavous, Shelton, \& Smith, 1997). Although the MIBI was developed for African Americans, the centrality dimension appears applicable to other group identities (Sellers, Smith, Shelton, Rowley, \& Chavous, 1998). African American and gay and lesbian participants completed equivalent versions of the centrality scale, which includes 10 items, such as "Overall being Black has very little to do with how I feel about myself" (reverse scored) and "Being Black is an important reflection of who I am." The gay and lesbian version substituted the acronym LGB for Black. Response options ranged from 1 (strongly disagree) to 7 (strongly agree). Reliability for this scale among experience sampling participants was high $(\alpha=.83)$.

Socioeconomic status (SES). A modified version of Hollingshead's (1975) index was used to assess current education level from 1 (less than 7 th grade) to 7 (graduate degree), total household income from 1 (less than $\$ 25,000$ ) to 6 (greater than $\$ 85,000$ ), and current occupation. Occupations were coded by two independent raters using Hollingshead's codes, which range from 1 (laborers and basic service workers) to 9 (executives, officials, and professionals). "Student," which is not included in Hollingshead's codes, was assigned a value of 5 , the scale midpoint. The average of the three measures (education, income, occupation) was used as the SES score. Interrater reliability was good (intraclass correlation coefficient of .82) and was assessed using an agreement approach (Shrout \& Fleiss, 1979).

Experience Sampling Survey. Because experience sampling studies involve large quantities of within-persons data, tests of reliability need to account for nonindependence. Bolger, Davis, and Rafaeli (2003) recommend that experience sampling researchers center data around each subject's mean to create a pooled within-subjects data matrix that can be tested using traditional reliability procedures (Cranford et al., 2006). Where reliability is reported for experience sampling instruments, we have adopted this approach. The order of instruments in this section is consistent with the order in which participants encountered the questions.

Interaction demographics. After each interaction, participants indicated whether their interaction was limited to one other person (i.e., dyadic), two other people, or three or more people (i.e., a group interaction). Gay and lesbian participants indicated whether interaction partners knew their sexual orientation. Only information from dyadic interactions is presented here. Participants also reported on how many years they had known their interaction partners.

Inhibition. Thirteen author-created items were included in the experience sampling survey to capture the concepts of negative affect and behavioral inhibition as described by the approach-inhibition theory of power (Anderson \& Berdahl, 2002; Keltner et al., 2003). ${ }^{4}$ According to the theory, one component of inhibition is negative affect, which includes negative emotions, anxiety, and self-consciousness (see Keltner et al., 2003, for a complete discussion of the inhibition system). Participants rated their experience of nine emotions (selfconscious, cautious, relaxed, inhibited, nervous, confident, alienated, comfortable, and insecure) after each interaction (e.g., "How relaxed did you feel during the interaction?") on a fully anchored scale from not at all to very (coded as 1 to 5), with a scale midpoint of somewhat. Selection of negative affect items was based on prior research using the approach-inhibition 
theory (Anderson \& Berdahl, 2002) and recent diary studies (Mendoza-Denton et al., 2002; Shelton et al., 2005).

We measured Keltner et al.'s (2003) conceptualization of behavioral inhibition with four self-report items about behavioral choices in the interaction, including "How much personal information did you reveal in the interaction?" "How free did you feel (or would you have felt) to express emotion?" "How free did you feel (or would you have felt) to express disagreement?" and "How genuine were you in the interaction?" These reverse-scored items were adapted from prior research examining participants' restriction of expression as a function of low power (Anderson \& Berdahl, 2002) and prior research suggesting minority participants' tendency toward inauthentic expression when expecting to be a target of prejudice (Shelton et al., 2005). Response options were presented on the same 5 -point scale as the negative affect items.

A principal components analysis (PCA) with varimax rotation yielded the hypothesized two components of negative affect and behavioral inhibition, which accounted for $55 \%$ of the variance. A second PCA specifying oblique rotation yielded the same factor structure with a .36 correlation between components, indicating that the negative affect and behavioral inhibition scales measure distinct constructs despite overlap. This separation is consistent with previous research, which has often found effects of power on behavioral, but not affective, outcomes (see Berdahl \& Martorana, 2006, for a review). The correlation between scales is consistent with the inhibition system that generates negative affect as well as behavioral inhibition (Keltner et al., 2003). The PCA was used to create separate negative affect and behavioral inhibition scales with alphas of .88 and .75 , respectively.

Subjective power. After each interaction, participants rated their sense of subjective power in the interaction, using eight items that were either modified from the Social Influence Scale (C. Anderson, personal communication, January 8, 2006) or were author generated. Example items include "My wishes didn't carry much weight in the interaction" (reverse scored) and "I led the conversation" (see Appendix A for a list of all items). Responses were provided on a fully anchored 4-point scale from disagree to agree (coded as 1 to 4). Because instrument piloting revealed that some of the power questions did not apply to particular interaction situations, a not applicable response was also included.

The not applicable responses were treated as missing data in the analysis. Because participants often chose not applicable for at least one of the power questions, initial reliability estimates (alpha $=.87$, mean interitem correlation $=.45$ ), were based on only 1,303 of 2,797 total interactions (46.6\%). To increase confidence in the reliability estimate, we implemented Enders's (2004) two-step procedure for estimating reliability in data sets with missing data using NORM software (Schafer, 1999) to impute missing data. Reliability estimates using the imputed data set yielded a coefficient alpha of .87 and a mean interitem correlation of 40 . The similarity between the analyses with imputed data and those with listwise deletion suggests the absence of a systematic pattern to the missing data and provides confidence that the mean of the eight original items (or valid subset) provides a reasonably reliable measure of subjective power.

Feeling stereotyped. After each interaction, participants answered the question "How likely is it that the other person stereotyped you?" using a fully anchored 5-point scale from not at all to very, with a scale midpoint of somewhat. Responses of somewhat, moderately, or very triggered an additional question about their attribution for stereotyping. Response options were gender, race/ethnicity, sexual orientation, and other (accompanied by a text box). Participants could choose multiple options. To avoid demand characteristics, these items were placed at the end of the Experience Sampling Questionnaire.

EOD Questionnaire. At the end of each day, participants were instructed to use an online questionnaire to answer whether they had (a) avoided interactions, (b) canceled a recording or deleted an audio file, and/or (c) neglected to complete a survey.

\section{Results}

Results begin with descriptive analyses, as well as checks for equivalency among our three subsamples. We next describe our multilevel model, which we use to test the primary hypotheses. We begin with the stereotype and power mediation hypotheses. Subsequently we turn to group differences, testing the stigma buffer hypothesis and then exploring differences between the two stigma groups.

\section{Preliminary Analyses}

We tested for differences in age, SES, and identity centrality between eligible participants who did complete the study and those who did not. None of these effects was significant. Among participants who completed the experience sampling study, there were no group differences in SES. Whereas neither stigmatized group differed in age from nonstigmatized participants $(M=24.27, S D=6.12)$, the gay and lesbian sample $(M=26.33$, $S D=7.66)$ was significantly older than the African American sample $(M=21.33, S D=2.44)$.

The final data set contained information from 2,060 dyadic interactions (approximately $75 \%$ of all interactions), with an average of 32.16 interactions per participant $(S D=15.40$, $M d n=29.50$, range $=6-90)$. These interactions took place with an average of 17.05 unique dyadic interaction partners $(S D=7.01, M d n=16.5$, range = 3-34). To test for group differences in the total number of interactions, we conducted a 3 (stigma status) $\times 2$ (gender) ANOVA. None of the omnibus effects reached the traditional .05 significance level, though there was a tendency for gay and lesbian participants to report more interactions $(M=38.62)$ than African American participants $(M=26.52)$. 
Table I. Between-Participants Correlations of Study Variables

\begin{tabular}{lccccc}
\hline Variables & $\mathrm{I}$ & 2 & 3 & 4 & 5 \\
\hline I. Negative affect & - & & & & \\
2. Behavioral inhibition & $.48^{* * * *}$ & - & & & \\
3. Subjective power & $-.55^{* * * *}$ & $-.5 \mathrm{I}^{* * *}$ & - & & \\
4. Feeling stereotyped & $.34^{* *}$ & $.25^{*}$ & $-.32^{* *}$ & - & \\
5. Identity centrality & -.06 & -.05 & -.20 & .22 & - \\
\hline
\end{tabular}

All variables except identity centrality were measured at each interaction and aggregated per person, $N=64$. Before aggregating, feeling stereotyped was transformed to a dichotomous variable where $0=$ not at all. Identity centrality was measured at the person level and in stigmatized participants only, $N=40$.

$*_{p} \leq .05 . * * p \leq .01$. **** $\leq .001$

The EOD questions, which asked about interactions that participants may have avoided or not reported, revealed no differences based on stigma status in the number of interactions avoided $(M=0.86, S D=1.88)$ or the number of times participants failed to complete surveys after interactions $(M=2.92$, $S D=4.64)$.

Table 1 presents correlations between study variables aggregated at the level of individual participants. At this level, correlations were in line with predictions. Feeling stereotyped was positively associated with greater feelings of negative affect and behavioral inhibition and lower feelings of subjective power (all $p s \leq .05$ ). As previously noted, negative affect and behavioral inhibition were positively correlated, and both were associated with lower power (all $p$ s $\leq .001$ ). Identity centrality was associated with lower aggregated social power and with a greater frequency of feeling stereotyped, but neither these nor any other effects involving centrality approached significance.

\section{Analysis Strategy}

Because of the nested within-participants data structure, the primary analyses use a multilevel strategy with restricted maximum likelihood estimation of model parameters. Figure 1 illustrates the multilevel structure. The between-participants level tests for individual differences in responses based, for example, on stigma status or gender. Nested within participants are their interaction partners. Analyses at this between-partners level test whether participants' responses differ by interaction partner. For example, does John Jones feel more or less powerful based on whether he is interacting with Ann or Bob? In some cases, participants interacted with the same person multiple times, which creates the last level of nesting. Analyses at this within-partners level test whether, for example, John Jones responds differently or consistently across multiple interactions with Ann.

Except where otherwise noted, multilevel analyses used the MIXED procedure of SAS 9.1. All analyses with stigma as a predictor also included gender and age as covariates.
Appendix B provides additional details, including methods used to calculate degrees of freedom and effect size estimates.

\section{Stereotype and Power Mediation Hypotheses}

As predicted by the stereotype hypothesis, when participants felt more stereotyped, they felt more inhibited, as indicated by greater negative affect and behavioral inhibition (see Table 2 for coefficients). This pattern held at all levels of analysis except for the within-partners effect for behavioral inhibition, which did not reach traditional significance levels but nevertheless had a medium-sized effect in the expected direction, $t(26.9)=$ $1.21, p=.25, d=0.47$. We also found support at every level of analysis for our hypothesis that feeling stereotyped is associated with reduced power (see Table 2). Participants were less likely to feel stereotyped by interaction partners they had known longer, $t(59)=-5.88, p<.001, d=-1.53$, an effect that did not vary by stigma group $(p s>.50)$.

Feeling stereotyped was also associated with lower power, and as shown in Table 3, lower power was associated with significant increases in negative affect and behavioral inhibition. Moreover, as shown in Figure 2, the effect of power on both inhibition outcomes remained significant even after controlling for participants feeling stereotyped (Baron \& Kenny, 1986; Krull \& MacKinnon, 2001), consistent with the power mediation hypothesis. However, despite an $18 \%$ reduction in the direct path from feeling stereotyped to negative affect and a $14 \%$ reduction in the direct path from feeling stereotyped to behavioral inhibition, both direct paths remained significant and relatively strong with power in the model. This reduction in path coefficients proved to be significant (Sobel, 1982) for both negative affect $(z=3.22)$ and behavioral inhibition $(z=$ $3.25)$, indicating that power provided partial mediation. ${ }^{6}$

\section{Stigma Buffer Hypothesis}

In this section, we focus on differences between stigmatized and nonstigmatized participants. We return to these analyses in the next section, where we examine differences between the two stigma groups. To test the stigma buffer hypothesis, we began by determining whether the likelihood of feeling stereotyped differed between stigma groups. Figure 3 provides the uncorrected proportion of interactions within each stigma group in which participants felt at least a little bit stereotyped. The no-stigma sample felt at least a little bit stereotyped in $17.7 \%$ of their dyadic interactions, whereas the gay and lesbian sample felt at least a little bit stereotyped in $21.7 \%$ and the Black sample in $31.1 \%$. To more formally test for stigma group differences and account for participant variability, we specified a multilevel model. Because the modal response to feeling stereotyped was not at all, we selected a Poisson-distributed outcome using HLM 6 and focused on population-average results (Raudenbush, Bryk, Cheong, \& Congdon, 2004). As 


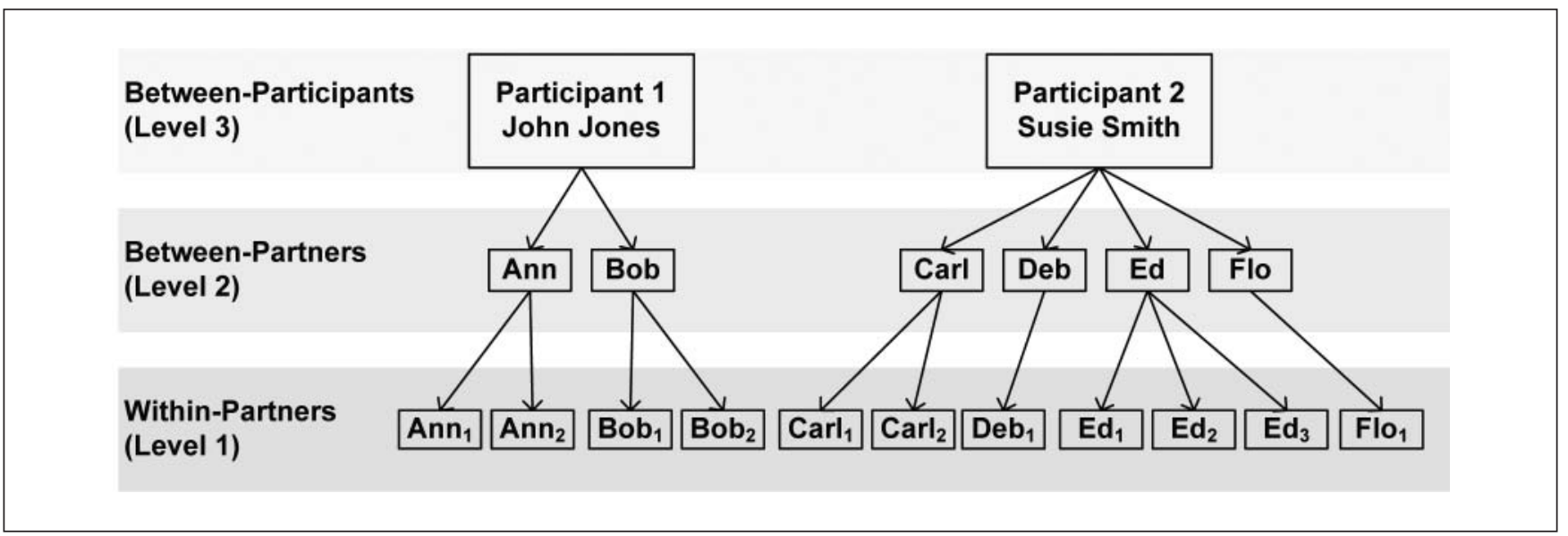

Figure I. Visual depiction of the multilevel structure

Table 2. The Impact of Feeling Stereotyped on Subjective Power and Inhibition

\begin{tabular}{lccc}
\hline & Power & Negative affect & Behavioral inhibition \\
\hline $\begin{array}{l}\text { Between participants } \\
\text { Mean level (intercept) }\end{array}$ & $3.19(0.04)^{* * *}$ & $1.65(0.04)^{* * *}$ & $2.53(0.05)^{* * *}$ \\
$\quad \begin{array}{l}\text { Aggregate stereotype } \\
\text { Between partners }\end{array}$ & $-0.33(0.11)^{* *}$ & $0.34(0.11)^{* *}$ & $0.28(0.16) \dagger$ \\
$\quad \begin{array}{l}\text { Effect of stereotype } \\
\text { Within partners }\end{array}$ & $-0.14(0.04)^{* * *}$ & $0.40(0.04)^{* * *}$ & $0.51(0.05)^{* * *}$ \\
$\quad$ Effect of stereotype & $-0.11(0.04)^{* *}$ & $0.20(0.06)^{* *}$ & $0.07(0.06)$ \\
\hline
\end{tabular}

Unstandardized coefficients are followed in parentheses by the standard errors for the estimates. $N=64$.

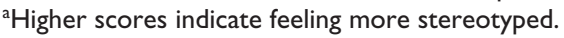

$\dagger p \leq .10$. ** $p \leq .01$. *** $p \leq .001$

Table 3. The Impact of Subjective Power on Inhibition

\begin{tabular}{lrlrr}
\hline & Negative affect & \multicolumn{1}{c}{$\begin{array}{l}\text { Behavioral } \\
\text { inhibition }\end{array}$} \\
\hline $\begin{array}{l}\text { Between participants } \\
\quad \text { Mean level (intercept) }\end{array}$ & 1.64 & $(0.03)^{* * * *}$ & 2.52 & $(0.04)^{* * * *}$ \\
$\quad \begin{array}{l}\text { Aggregate power } \\
\text { Between partners }\end{array}$ & -0.56 & $(0.10)^{* * *}$ & -0.67 & $(0.14)^{* * *}$ \\
$\quad \begin{array}{lllll}\text { Effect of power (intercept) } \\
\text { Within partners }\end{array}$ & -0.48 & $(0.05)^{* * *}$ & -0.57 & $(0.05)^{* * *}$ \\
$\quad$ Effect of power (intercept) & -0.35 & $(0.05)^{* * *}$ & -0.35 & $(0.04)^{* * *}$ \\
\hline
\end{tabular}

Unstandardized coefficients are followed in parentheses by the standard errors for the estimates. $N=64$.

aHigher scores indicate that a participant felt more powerful.

$* * * p \leq .001$

expected, the odds of feeling stereotyped during the study were significantly higher for stigmatized participants, $t(59)=$ $-2.09, p=.04, d=-0.54$.

Reasons for feeling stereotyped were only requested when participants reported feeling at least somewhat stereotyped (i.e., not for responses of feeling a little bit stereotyped). When nonstigmatized participants felt stereotyped, it was mostly because of "other" reasons they wrote in (see Table 4). These responses most often involved age or appearance but occasionally involved race or sexual orientation as well. Gay and lesbian and African American participants most frequently indicated feeling stereotyped because of sexual orientation and race, respectively. Gay and lesbian participants also commonly selected "other" reasons, but there was no clear pattern to the other responses, which included reasons such as job, religion, and appearance. African American participants had a relatively high frequency of feeling stereotyped because of their gender.

Since feeling stereotyped was associated with lower power and higher inhibition, and since stigmatized participants were more likely to feel stereotyped, one might expect from base rates that stigmatized participants should have lower average levels of power and higher average levels of inhibition. This was not the case. Consistent with the stigma buffer hypothesis, there were virtually no differences between the nonstigmatized and the combined stigmatized samples in average levels of 

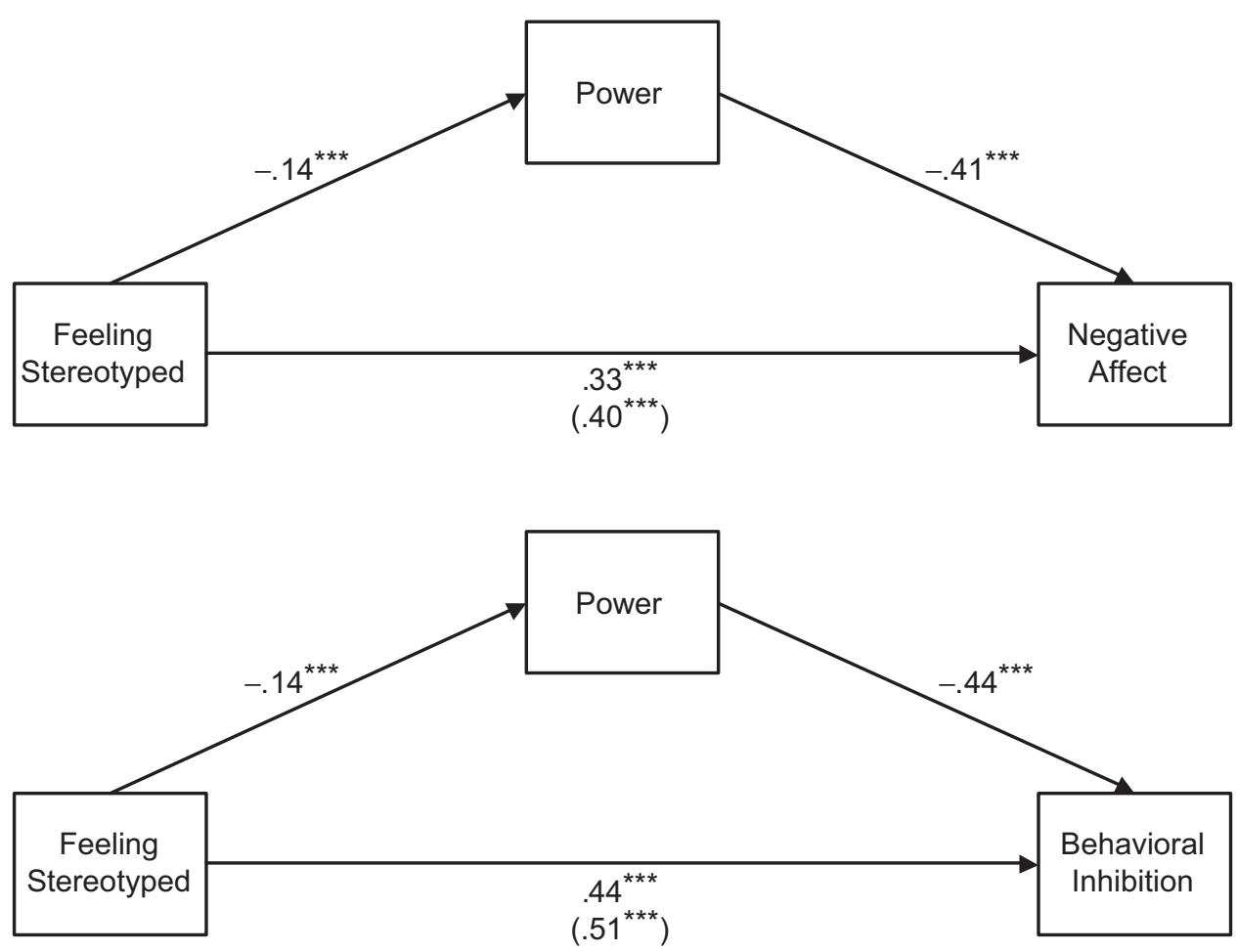

Figure 2. Power as a partial mediator of feeling stereotyped on negative affect (top) and behavioral inhibition (bottom) The unmediated coefficient for feeling stereotyped is in parentheses.

$* * * \mathrm{p} \leq .001$

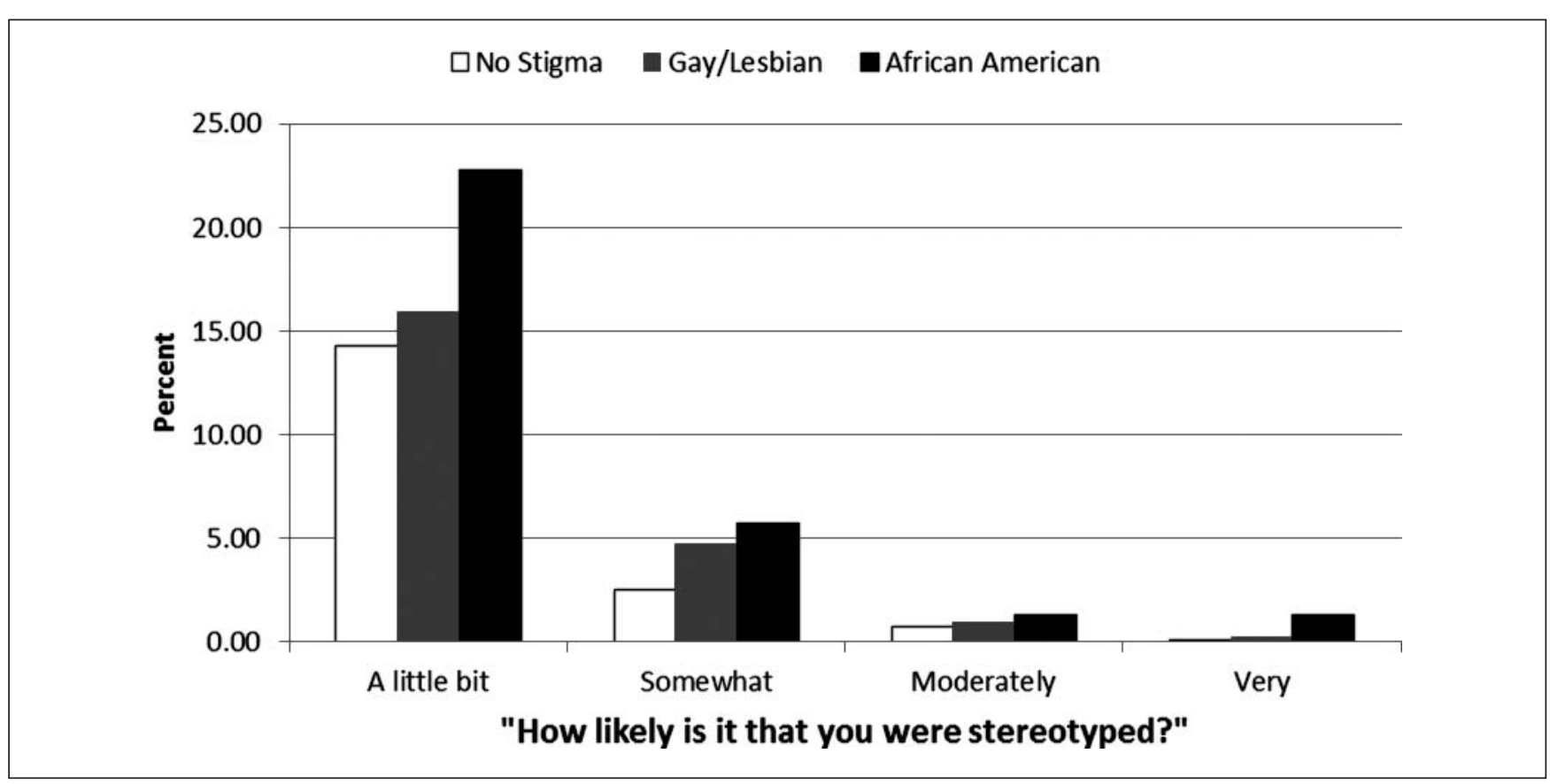

Figure 3. Proportion of interactions within each stigma group in which participants felt there was some likelihood they were stereotyped by partners

Scores on the $x$-axis represent the original scale of the stereotype question. Responses are uncorrected for the number of interactions participants reported. 
Table 4. Reasons for Feeling Stereotyped as a Function of Stigma Group

\begin{tabular}{lccc}
\hline & No stigma & $\begin{array}{c}\text { Gay and } \\
\text { lesbian }\end{array}$ & $\begin{array}{c}\text { African } \\
\text { American }\end{array}$ \\
\hline Race & 4 & 3 & 29 \\
Sexual orientation & 2 & 24 & 5 \\
Gender & 3 & 10 & 19 \\
Other & 15 & 23 & 9 \\
\hline
\end{tabular}

Reasons for feeling stereotyped were only reported when participants felt at least somewhat stereotyped. Participants could choose multiple categories for a single interaction. Responses are uncorrected for the number of interactions participants reported.

power $(M \mathrm{~s}=3.20,3.23$, and 3.13 for the nonstigmatized, gay and lesbian, and Black samples, respectively), negative affect $(M \mathrm{~s}=1.67,1.68$, and 1.63, respectively), or behavioral inhibition $(M \mathrm{~s}=2.58,2.62$, and 2.49, respectively; all $p \mathrm{~s}>.60)$. These results suggest that stigmatized participants were able to buffer the effect of feeling stereotyped.

Moreover, if experience with a stigmatized identity helps buffer the consequences of feeling stereotyped, stigma should moderate how feeling stereotyped is experienced. Consistent with the buffering hypothesis, nonstigmatized participants had a stronger inhibitory response to feeling stereotyped by specific partners (between-partners level) than did members of stigmatized groups (see Figure 4). Nonstigmatized participants felt more negative affect, $t(44.5)=2.61, p=.01, d=0.78$, and behavioral inhibition, $t(29.7)=2.04, p=.05, d=0.75$, than stigmatized participants when they felt stereotyped. ${ }^{7}$ Stigma group did not significantly moderate the effect of feeling stereotyped on power $(p s>.50)$. This suggests that differences in coping between nonstigmatized and stigmatized individuals may operate primarily through inhibition, not through power.

\section{Differences by Stigma Group}

Whereas the previous section reported results comparing the no-stigma sample with the combined stigma group sample, this section reports results comparing African Americans with gays and lesbians. Like the previous section, results presented here test for differences in the frequency of feeling stereotyped and in average levels of inhibition and power. They also test for any moderating effect of stigma group on the effect of feeling stereotyped. Because additional data on identity centrality were collected from the two stigma groups, this section also tests whether African Americans had higher centrality than gay and lesbians, and if so, whether centrality might account for any differences that emerged between the two groups.

Our exploratory investigation into differences between the two stigma groups began with the hypothesis that African Americans would have higher identity centrality than gays and lesbians. Results supported this hypothesis. African
American participants had significantly higher centrality $(M=5.19, S D=1.23)$ than gay and lesbian participants $(M=4.08, S D=0.95), t(38)=-3.22, p<.01, d=1.04$.

The two stigma groups did not differ significantly in their likelihood of feeling stereotyped, $t(59)=-0.90, p=.37$, $d=-0.23$. As reported previously, the mean levels of power and inhibition over the duration of the study were very similar between the African American and gay and lesbian samples and did not significantly differ (all $p \mathrm{~s}>.40$ ).

Does stigma group moderate how feeling stereotyped relates to inhibition or power? In the previous section, the contrast comparing nonstigmatized with stigmatized participants moderated how feeling stereotyped was associated with inhibition but not power. Similarly, the contrast comparing the two stigma groups also moderated inhibition (see below) but not power ( $p \mathrm{~s}>.50$ ). The moderating effect of stigma group on the relation between feeling stereotyped and feeling inhibited is presented next.

African American and gay and lesbian participants differed in the strength of relation between feeling stereotyped and inhibition. When participants had repeated interactions with the same partner (i.e., within-partners level), a perception of feeling stereotyped in at least one of those interactions was associated with greater behavioral inhibition for gay and lesbian participants than for African American participants, $t(18.8)=1.96, p=.06, d=0.90$. That is, African American participants appeared to be less reactive.

Perhaps African Americans were less reactive because they had greater identity centrality. To examine the role of identity centrality in this difference, we had to specify a reduced model (with lower statistical power) that included only stigmatized participants because identity centrality was not assessed in the no-stigma sample. In the reduced-sample reanalysis, three differences between African American and gay and lesbian participants emerged before controlling for centrality. When feeling stereotyped in repeated interactions with the same partner (within-partners level), African American participants continued to exhibit an attenuated behavioral inhibition response, $t(15.7)=1.80, p=.09, d=0.91$, and were less reactive in their negative affect, $t(17.3)=1.88, p=.08, d=0.90$. In addition, when they felt stereotyped by a particular partner (between-partners level), African American participants also showed a weaker behavioral inhibition response than gays and lesbians, $t(3.96)=2.36, p=.08, d=2.74 .{ }^{8}$ After controlling for centrality, the within-partners effects remained for behavioral inhibition, $t(46.1)=2.44, p=.02, d=0.72$, and for negative affect, $t(31.6)=1.87, p=.07, d=.67$. By contrast, the between-partners effect for behavioral inhibition disappeared, $t(26.8)=-0.23, p=.82, d=0.09$. Thus, identity centrality accounted for differences in inhibition between African American and gay and lesbian participants in response to feeling stereotyped at the between-partners level but not at the within-partners level. This suggests that centrality provides protection with certain types of high-risk partners (e.g., strangers), perhaps by increasing the expectation of feeling stereotyped, 


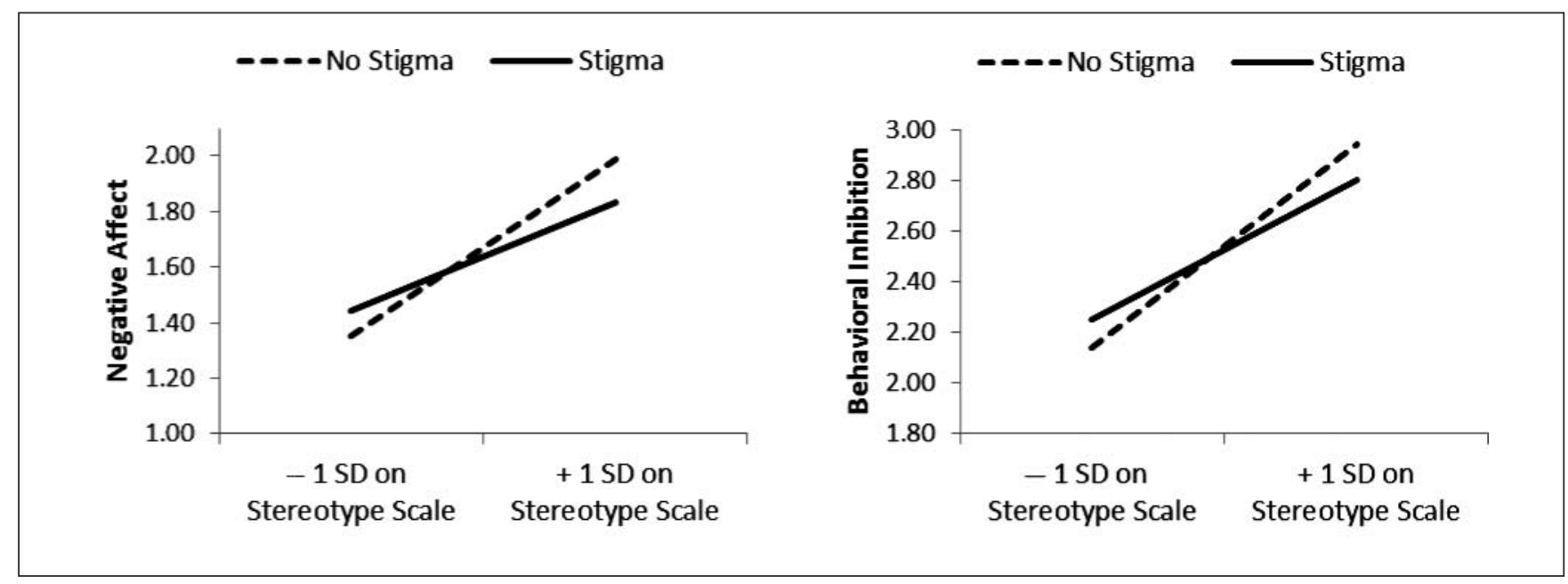

Figure 4. Effect of feeling stereotyped on negative affect (left) and behavioral inhibition (right) as a function of participant stigma status Predicted values were computed at I SD below and above the mean between-partners standard deviation for feeling stereotyped.

an expectation that would be less anticipated in an interaction with a member of one's regular group of supportive acquaintances.

Was sexual orientation concealed? As an ancillary exploratory analysis, we further examined gay and lesbian participants' responses to feeling stereotyped because of sexual orientation. As previously discussed, one of the possible differences between a stigma based on sexual orientation and one based on race or ethnicity is the potential for concealability. However, if gay and lesbian participants felt stereotyped because of their sexual orientation, their stigmatized identity may not have been concealed. Indeed, in nearly all of the interactions where gay and lesbian participants reported feeling stereotyped because of their sexual orientation (93\%), their partner knew their sexual orientation. This suggests an interesting consequence of stigma concealability. People with concealable stigmas may be more likely to feel stereotyped by known acquaintances, whereas people with visible stigmas may be more likely to feel stereotyped by strangers or infrequent interaction partners. Consistent with this idea, gay and lesbian participants had multiple interactions with $38.5 \%$ of partners who they felt had stereotyped them because of sexual orientation. African American participants had multiple interactions with only $10.5 \%$ of partners who they felt had stereotyped them because of their race.

\section{Discussion}

This study examined the relation between feeling stereotyped, social power, and inhibition. We begin the discussion with the results of the primary hypotheses, which examined the effects of feeling stereotyped on power and inhibition, as well as the mediating and direct relations of power with inhibition. We then discuss whether these relations differed among stigmatized and nonstigmatized groups.

\section{Stereotypes, Power, and Inhibition}

Participants' subjective assessments of everyday interactions support the hypothesis that when people feel stereotyped, they feel greater inhibition in the form of negative affect and behavioral restraint. When considered with other relevant research, these results make it plausible that the situational activation of a marginalized social identity might be conceptualized as part of a coherent inhibition response. Such a conceptualization provides a convenient framework for thinking about the effects of social identity threat (Steele et al., 2002) and supports a growing research trend in which the effects of a marginalized identity are seen in the context of general psychological mechanisms (Miller, 2006; Swim \& Thomas, 2006).

Feeling stereotyped was also predictive of low power, and power partially mediated the relation between feeling stereotyped and inhibition. Thus, inhibition as a consequence or correlate of feeling stereotyped is to some extent a reaction to feeling relatively powerless. Other known consequences of feeling stereotyped could also be characterized as consequences of low power. For instance, reduction of working memory mediates the effect of stereotype threat on performance (Schmader \& Johns, 2003), but similar disruptions to working memory are hypothesized from low power (Keltner et al., 2003). Likewise, when identity threat increases self-regulatory efforts (Richeson \& Shelton, 2007), it requires self-control (Inzlicht, McKay, \& Aronson, 2006), and controlled social cognition is also thought to result from low power (Keltner et al., 2003). More research is needed to determine how power relates to these effects and whether, as suggested here, the path from identity threat to inhibition includes multiple mediatorsacting concurrently or serially.

We also tested the association between low power and inhibition independently. In the entire sample, lower levels of subjective power in dyadic interactions were associated with 
higher levels of negative affect and behavioral inhibition, supporting the model of power advanced by Keltner et al. (2003). This result was found at every level of analysis, whether in a particular interaction or with a particular partner or between participants using average ratings of power. Because of the correlational design, it is possible that results could actually be driven by the disinhibiting effects of high power rather than the inhibiting effects of low power, but we believe this is unlikely given the relation between feeling stereotyped and power. Feeling stereotyped was relatively infrequent, suggesting that losing power is a more likely causal trigger of changed experiences than participants' potential feelings of gained power in the baseline experiences of not being stereotyped. Similarly, it seems unlikely that feeling stereotyped was a consequence (rather than a cause) of inhibition or low power since participants did not feel stereotyped in the majority of interactions that caused them to feel low in power and inhibited.

\section{Differences Between Stigma Groups}

Majority group membership does not shield people from the experience of being stereotyped (Vorauer et al., 1998), even though stigmatized participants are generally more likely to feel stereotyped. In this study, the "nonstigmatized" sample reported feeling stereotyped because of age, appearance, and gender, and occasionally because of ethnicity and sexual orientation. The stigmatized samples also felt stereotyped because of these identities, but as would be expected, gay and lesbian participants most frequently reported stereotypes related to sexual orientation, and African American participants most frequently reported stereotypes related to ethnicity.

Although the stigmatized sample was significantly more likely to feel stereotyped and feeling stereotyped was associated with lower power and higher inhibition, we found no differences between the stigmatized and nonstigmatized samples in average levels of power and inhibition averaged across all interactions. How do we reconcile this discrepancy? We believe that, over time, greater frequency of experience with stereotypes leads to something akin to "practice effects" (see also Inzlicht, Aronson, et al., 2006; Smart \& Wegner, 2000) that helps buffer the negative consequences of feeling stereotyped. In coping language (Lazarus \& Folkman, 1984), members of stigmatized groups learn to tolerate, minimize, accept, or ignore stereotypic beliefs directed at them. Thus, our research hints at the presence of coping beyond more effortful strategies (e.g., Crocker \& Major, 1989) to include more automatized processes, which are "just as important in the person's adaptational armamentarium" (Lazarus \& Folkman, 1984, p. 139). Members of nonstigmatized groups are less defended and thus more reactive in those (unusual) instances in which they feel stereotyped.

Research that includes multiple stigma groups is unusual, and hence our analyses with respect to differences between gay and lesbian and African American participants were largely exploratory. In general, the responses of these two groups were more similar than different, but some interesting differences emerged. Although these differences were relatively small, it is important to note that they emerged in the chaotic world of everyday social interaction, where it can be difficult to isolate psychological processes. Consequently, a relatively weak effect that emerges in the field may be particularly meaningful.

The clearest difference between the two groups was in the centrality of the stigmatized identity, with African American participants being significantly more identified than gay and lesbian participants. African Americans also seemed to be less sensitive than gay and lesbian participants to the inhibitory effects of feeling stereotyped. Given African Americans' higher levels of identity centrality, one explanation is that African Americans reap the benefits of higher group identification (Bourguignon et al., 2006; Branscombe et al., 1999). Partial support for this explanation can be found in the betweenpartners effect of feeling stereotyped on behavioral inhibition. African Americans were less inhibited than gays and lesbians when they felt stereotyped by interaction partners, but when identity centrality was statistically controlled, this difference disappeared.

But identity centrality clearly is not the whole story. Centrality did not account for African Americans' lower reactivity (in both behavioral inhibition and negative affect) when participants reported multiple interactions with a partner and felt stereotyped in at least one of them. Perhaps this difference is related to other dimensions of stigma concealability. Our results suggest that gay and lesbian participants were more likely to feel stereotyped by known acquaintances who knew their sexual orientation, whereas African American participants were more likely to feel stereotyped by one-time interaction partners. For gays and lesbians, a decision to disclose sexual orientation may be made primarily to people who are expected to be supportive. To be stereotyped by such a person thus may be particularly inhibiting. Alternatively, because sexual orientation is not always on display (as skin color is), gays and lesbians may have lower levels of momentary identity salience or may come to feel that their sexual orientation is not particularly salient for known interaction partners. Consequently, it is surprising to feel stereotyped in a way that it might not be with new acquaintances or known "homophobes" where stereotyped treatment (and thus identity salience) might be more likely. Another possibility is that these within-partners differences could be due to the specific nature of gay and lesbian versus African American identity. Because homosexuality is often seen as a violation of gender norms (Ambady, Hallahan, \& Conner, 1999; Whitley, 2001) and gays and lesbians are certainly aware of stereotypes associated with homosexuality (Major, 2006), it may be that when gays and lesbians felt stereotyped by a known partner, they made a concerted effort to rein in behaviors that might confirm the stereotype (and possibly threaten a relationship). More research is needed to explore differences based on stigma concealability. Given variation in the types of situations that elicited feeling stereotyped 
(e.g., one-time vs. regular partners), designs that include a within-subjects component may be particularly appropriate.

\section{Conclusions}

At best, being the target of prejudice and discrimination is unpleasant, socially isolating, and a barrier to material resources; at worst, it can result in physical attacks, bodily harm, and death. It is not surprising, then, that a common theme in stigma research is that when people feel marginalized because of a social identity it evokes feelings of threat. We have proposed and found support for the idea that these feelings of threat can be conceptualized as part of a broader inhibition system, activated upon stereotypic treatment, and partially mediated by low power. Most people feel stereotyped at least sometimes, and members of stigmatized groups feel stereotyped more often. If there is a silver lining to having a stigmatized identity, perhaps it is greater resilience against the negative results of being stereotyped.

\section{Appendix A}

\section{Subjective Power Scale}

1. My wishes didn't carry much weight in the interaction. (R)

2. I was able to get my way in the interaction.

3. I had a great deal of power in the interaction.

4. I had an influence on decisions in the interaction.

5. My ideas and opinions were often ignored in the interaction. ( $\mathrm{R}$ )

6. My conversation partner(s) listened to what I said.

7. I led the conversation.

8. I was in control of the interaction.

\section{Appendix B}

\section{Specification of Model, Degrees of Freedom, and Effect Size Estimates}

Because negative affect and behavioral inhibition scales were correlated, these variables were modeled together using a multivariate, repeated measures approach, which provides separate coefficients for each dependent variable after accounting for their covariance (see Gao, Thompson, Xiong, \& Miller, 2006). We specified an unstructured compound symmetry matrix for the multivariate data and allowed the covariance of random terms to be freely estimated. Degrees of freedom were calculated using the Kenward-Roger (KR) method. Although the KR method appears to be the least biased for complex covariance structures (Littell, 2006; Schaalje, McBride, \& Fellingham, 2001), it yields degrees of freedom that are not necessarily whole numbers and that vary considerably between analyses. These degrees of freedom were used to calculate estimates of effect size based on Rosnow and Rosenthal's (1996) formula for calculating Cohen's $d$ using the $t$ statistic and degrees of freedom.

\section{Sample Equations of the Multilevel Models}

Level I equations. Mathematically, the within-partners Level 1 model is

$$
Y_{i j k}=\pi_{0 j k}+e_{i j k}
$$

where $Y$ (i.e., power or inhibition) is a function of an intercept representing a mean across interactions $\left(\pi_{0 j k}\right)$ plus random error $\left(e_{i j k}\right)$. After each interaction, participants reported whether they felt stereotyped, and this information was modeled at Level 1, as shown in Equation B1.1:

$$
\left.Y_{i j k}=\pi_{0 j k}+\pi_{1 j k} \text { Stereotype }_{i j k}-\overline{\text { Stereotype }}_{. j k}\right)+e_{i j k}
$$

In Equation B1.1, the effect of feeling stereotyped is groupmean centered. Because Level 1 data are nested within unique interaction partners, the coefficient $\pi_{1 j k}$ represents the effect of feeling stereotyped across multiple interactions with a typical interaction partner. Power was included as a Level 1 predictor and was also group-mean centered, as shown in Equation B1.2.

$$
Y_{i j k}=\pi_{0 j k}+\pi_{1 j k}\left(\text { Power }_{i j k}-{\overline{\text { Power }_{. j k}}}\right)+e_{i j k}
$$

Level 2 equations. The Level 2 equations specify sources of variation in Level 1 coefficients as a function of interaction partner characteristics. The most basic Level 2 model,

$$
\pi_{0 j k}=\beta_{00 k}+r_{0 j k}
$$

simply specifies random variation in the intercept across participants' interaction partners. Participants' feelings of power and inhibition were allowed to vary freely across interaction partners. Because group-mean centering at Level 1 results in the removal of between-groups variance at higher levels (Raudenbush \& Bryk, 2002), we included the aggregates of lower level variables as predictors of the intercept at Levels 2 and 3 .

Equations B2.1a and B2.1b provide examples of Level 2 equations based on a model with stereotype as a Level 1 predictor:

$$
\begin{gathered}
\pi_{0 j k}=\beta_{00 k}+\beta_{01 k}\left(\text { Stereotype }_{i j k}-\overline{\text { Stereotype }}_{. k}\right)+r_{0 j k} \\
\pi_{1 j k}=\beta_{10 k} .
\end{gathered}
$$

Equation B2.1a models variation in the intercept accounting for variability across participants' aggregated feeling of being stereotyped by unique partners. ${ }^{9}$ Equation B2.1b specifies that 
the effect of feeling stereotyped in an interaction does not vary across interaction partners. Equations B2.2a and B2.2b display the equivalent models for power:

$$
\begin{gathered}
\pi_{0 j k}=\beta_{00 k}+\beta_{01 k}\left(\text { Power }_{j k}-\overline{\text { Power }}_{\cdot k}\right)+r_{0 j k} \\
\pi_{1 j k}=\beta_{10 k} .
\end{gathered}
$$

Level 3 equations. At Level 3, between-participants differences in slopes and intercepts are modeled. The most simple Level 3 model, corresponding to Equations B1 and B2, is

$$
\begin{aligned}
\beta_{00 k} & =\gamma_{000}+\gamma_{001}\left(\text { Gender }_{k}-\overline{\text { Gender }_{.}}\right) \\
& +\gamma_{001}\left(\text { Age }_{k}-\overline{\text { Age }}\right)+\gamma_{002}\left(\text { StigmaC }_{k}\right) \\
& +\gamma_{003}\left(\text { StigmaC }_{k}\right)+u_{00 k}
\end{aligned}
$$

where the intercept is modeled as a function of participant gender, age, stigma status, and random variation. To facilitate interpretation of the intercept, gender and age are grand-mean centered, making the intercept the average level of the dependent variable, controlling for gender and age. Stigma status was a three-level variable (no stigma, gay and lesbian, and African American) entered as two orthogonal Helmert contrasts. The first contrast (StigmaC1) compares nonstigmatized participants with stigmatized participants (gay/lesbian and African American combined), using weights of 2 and -1 , respectively. The second contrast (StigmaC2) compares gay and lesbian participants with African American participants, using a weighting scheme of 0 (nonstigmatized), 1 (gay and lesbian), and -1 (African American).

Raudenbush and Bryk (2002) recommend modeling a common set of variables in the highest level equations, and this is the approach we adopted. As in the Level 2 equations, the aggregate of lower level group-mean centered variables were entered as predictors of the intercept at Level 3. Like gender and age, these aggregates were grand-mean centered at Level 3. All Level 2 intercepts and slopes were allowed to vary randomly at Level 3.

\section{Authors' Note}

Jonathan E. Cook, Holly Arrow, and Bertram F. Malle were all at the Department of Psychology and members of the Institute for Cognitive and Decision Sciences at the University of Oregon when this study was completed.

Jonathan Cook is now at the Department of Psychology, Columbia University, and Bertram Malle is at the Department of Psychology, Brown University.

This research was conducted in partial fulfillment of the first author's doctoral dissertation. We would like to thank Justine Calcagno, Geoff Cohen, Nathan Dieckmann, Robin High, and Sanjay Srivastava for their comments and assistance, and study participants for their willingness to document their interactions.

\section{Declaration of Conflicting Interests}

The authors declared no potential conflicts of interest with respect to the authorship and/or publication of this article.

\section{Funding}

The authors disclosed receipt of the following financial support for the research and/or authorship of this article: support from the Institute for Cognitive and Decision Sciences at the University of Oregon, a Research Scholarship from the American Psychological Association of Graduate Students, and a research award from the Center on Diversity and Culture at the University of Oregon.

\section{Notes}

1. Audio data are not presented here.

2. This participant, a self-described heterosexual male, described a male interaction partner as his boyfriend, raising questions as to the authenticity of the data. This participant also reported on a total of only 10 interactions over the week, fewer than required, thus warranting removal.

3. After finding that 10 surveys a day was challenging for most participants, we set a minimum goal of 5 per day (on average).

4. Although Carver and White's (1994) Behavioral Inhibition System/Behavioral Approach System scales are commonly used to measure inhibition and approach, and although there is some precedent to their use as a state assessment (Smith \& Bargh, 2008), the instrument is designed to measure individual differences rather than transient states. The content of the BIS items (e.g., "I have very few fears compared to my friends" and "I worry about making mistakes") are highly dispositional in nature and preclude their practical use in an experience sampling study where participants respond to the same items repeatedly each day. Moreover, a recent psychometric evaluation of the BIS/ BAS scales revealed poor fit to the hypothesized factor structure and unexpected correlations among the scales, raising conceptual questions about the instrument's interpretation (Cogswell, Alloy, van Dulmen, \& Fresco, 2006). Taken together, and given the goals of the current research, we felt justified in relying on face-valid scales directly targeting the hypothesized affective and behavioral dimensions of inhibition.

5. Measuring momentary feelings of being stereotyped in the field is largely without precedent. We wanted to find a way to assess feeling stereotyped, equivalently across groups and in a way that would be unobtrusive with respect to the particular identity that had been stereotyped. Our single-item question is a state-level adaptation of stigma consciousness, which is defined as "an expectation that one will be stereotyped" (Pinel, 1999, p. 115). It is similar to a question from a naturalistic study on perceiver effects of being stereotyped (L. L. Cohen \& Swim, 1995), and its directness is similar to the daily assessment of rejection by Mendoza-Denton, Downey, Purdie, Davis, and Pietrzak (2002). Single-item measures often display psychometric properties that are similar to multi-item scales of similar constructs (Robins, Hendin, \& Trzesniewski, 2001) and have shown predictive validity 
in recent studies of self-esteem (Robins et al., 2001) and racial identification (G. L. Cohen \& Garcia, 2005). That participants may have partially relied on metastereotypes (Vorauer, Main, \& O'Connell, 1998) should not affect results; regardless of accuracy, if participants felt stereotyped, we expected to see a reduction in power and increase in inhibition.

6. Perhaps the causal order is not that feeling stereotyped leads to powerlessness and inhibition but that powerlessness and inhibition cause people to feel stereotyped. Ancillary analyses suggest this is unlikely, as people often felt low in power and inhibited without feeling stereotyped. Most instances of low power and inhibition (i.e., the majority of interactions in the lowest quartile of power and the top quartile of inhibition, after centering within participants) were not associated with feeling stereotyped. This makes sense because people can feel powerless for a variety of reasons that are not related to being stereotyped. In contrast, when participants did feel stereotyped, the highest proportion of responses was associated with low power and inhibition.

7. That this result occurs at the between-partners level reflects the naturalistic structure of the study. People can be expected to generally surround themselves with others who are accepting and who view them as individuals. Across multiple interactions with these preferred partners (within-partners variance) there was indeed little variability of feeling stereotyped-only $25 \%$ of the total. Instead, $62 \%$ of the variance in feeling stereotyped was between partners, usually when participants only interacted with a partner once or, in some cases, with individuals who consistently stereotyped them. The remaining $13 \%$ of variance in feeling stereotyped was between participants.

8. As described in Appendix B, degrees of freedom were estimated using the Kenward-Roger method in SAS, which results in considerable variation from analysis to analysis. Although the degrees of freedom for this analysis are low, the pattern of results for these analyses remains the same if we take a univariate approach to the data analysis with other software, where degrees of freedom conform to more normal expectations.

9. Although we expected the intercept to vary, we had no a priori reason to expect random variation in Level 1 slopes between interaction partners. Nevertheless, across a variety of models we tested the statistical tenability of random slopes. The result was typically slow convergence, suggesting that the data were "relatively sparse" (Raudenbush \& Bryk, 2002, p. 257), most likely because participants usually had a small number of interactions with most partners, leading to insufficient within-partner variability to estimate an error term (Raudenbush, Bryk, Cheong, \& Congdon, 2004).

\section{References}

Adams, G., Tormala, T. T., \& O'Brien, L. T. (2006). The effect of self-affirmation on perception of racism. Journal of Experimental Social Psychology, 42, 616-626.

Ambady, N., Hallahan, M., \& Conner, B. (1999). Accuracy of judgments of sexual orientation from thin slices of behavior. Journal of Personality and Social Psychology, 77, 538-547.
Anderson, C., \& Berdahl, J. L. (2002). The experience of power: Examining the effects of power on approach and inhibition tendencies. Journal of Personality and Social Psychology, 83, 1362-1377.

Anderson, C., \& Galinsky, A. D. (2006). Power, optimism, and risktaking. European Journal of Social Psychology, 36, 511-536.

Baron, R. M., \& Kenny, D. A. (1986). The moderator-mediator variable distinction in social psychological research: Conceptual, strategic and statistical considerations. Journal of Personality and Social Psychology, 51, 1173-1182.

Berdahl, J. L., \& Martorana, P. (2006). Effects of power on emotion and expression during a controversial group discussion. European Journal of Social Psychology, 36, 497-509.

Bolger, N., Davis, A., \& Rafaeli, E. (2003). Diary methods: Capturing life as it is lived. Annual Review of Psychology, 54, 579-616.

Bourguignon, D., Seron, E., Yzerbyt, V., \& Herman, G. (2006). Perceived group and personal discrimination: Differential effects on personal self-esteem. European Journal of Social Psychology, 36, 773-789.

Branscombe, N. R., Schmitt, M. T., \& Harvey, R. D. (1999). Perceiving pervasive discrimination among African Americans: Implications for group identification and well-being. Journal of Personality and Social Psychology, 77, 135-149.

Carver, C. S., \& White, T. L. (1994). Behavioral inhibition, behavioral activation, and affective responses to impending reward and punishment: The BIS/BAS Scales. Journal of Personality and Social Psychology, 67, 319-333.

Christensen, T. C., Barrett, L. F., Bliss-Moreau, E., Lebo, K., \& Kaschub, C. (2003). A practical guide to experience-sampling procedures. Journal of Happiness Studies, 4, 53-78.

Cialdini, R. B. (2009). We have to break up. Perspectives on Psychological Science, 4, 5-6.

Cogswell, A., Alloy, L. B., van Dulmen, M. H. M., \& Fresco, D. M. (2006). A psychometric evaluation of behavioral inhibition and approach self-report measures. Personality and Individual Differences, 40, 1649-1658.

Cohen, G. L., \& Garcia, J. (2005). "I am us": Negative stereotypes as collective threats. Journal of Personality and Social Psychology, 89, 566-582.

Cohen, L. L., \& Swim, J. K. (1995). The differential impact of gender ratios on women and men: Tokenism, self-confidence, and expectations. Personality and Social Psychology Bulletin, 21, 876-884.

Cranford, J., Shrout, P., Iida, M., Rafaeli, E., Yip, T., \& Bolger, N. (2006). A procedure for evaluating sensitivity to within-person change: Can mood measures in diary studies detect change reliably? Personality and Social Psychology Bulletin, 32, 917-929.

Crocker, J., \& Major, B. (1989). Social stigma and self-esteem: The self-protective properties of stigma. Psychological Review, 96, 608-630.

Dovidio, J. F., Major, B., \& Crocker, J. (2000). Stigma: Introduction and overview. In T. F. Heatherton, R. E. Kleck, M. R. Hebl, \& J. G. Hull (Eds.), The social psychology of stigma (pp. 1-28). New York, NY: Guilford. 
Eccleston, C. P., \& Major, B. (2006). Attributions to discrimination and self-esteem: The role of group identification and appraisals. Group Processes Intergroup Relations, 9, 147-162.

Enders, C. K. (2004). The impact of missing data on sample reliability estimates: Implications for reliability reporting practices. Educational and Psychological Measurement, 64, 419-436.

Fiske, S. T. (2004). Social beings: A core social motives approach to social psychology. New York, NY: Wiley.

Fiske, S. T., Xu, J., Cuddy, A. C., \& Glick, P. (1999). (Dis)respecting versus (dis)liking: Status and interdependence predict ambivalent stereotypes of competence and warmth. Journal of Social Issues, 55, 473-489.

French, J., \& Raven, B. H. (1959). The bases of social power. In D. Cartwright (Ed.), Studies in social power (pp. 150-167). Ann Arbor, MI: Institute for Social Research.

Galinsky, A. D., Gruenfeld, D. H., \& Magee, J. C. (2003). From power to action. Journal of Personality and Social Psychology, 85, 453-466.

Gao, F., Thompson, P., Xiong, C., \& Miller, P. J. (2006, March). Analyzing multivariate longitudinal data using SAS (Paper 18731). Paper presented at the annual SAS Users Group international conference, San Francisco, CA.

Gray, J. A. (1994). Three fundamental emotion systems. In P. Ekman \& R. J. Davidson (Eds.), The nature of emotion (pp. 243-247). New York, NY: Oxford University Press.

Guinote, A. (2007a). Power affects basic cognition: Increased attentional inhibition and flexibility. Journal of Experimental Social Psychology, 43, 685-697.

Guinote, A. (2007b). Power and goal pursuit. Personality and Social Psychology Bulletin, 33, 1076-1087.

Hebl, M. R., \& Dovidio, J. F. (2005). Promoting the "social" in the examination of social stigmas. Personality and Social Psychology Review, 9, 156-182.

Hollingshead, A. B. (1975). Four factor index of social status. New Haven, CT: Yale University Press.

Inzlicht, M., Aronson, J., Good, C., \& McKay, L. (2006). A particular resiliency to threatening environments. Journal of Experimental Social Psychology, 42, 323-336.

Inzlicht, M., McKay, L., \& Aronson, J. (2006). Stigma as ego depletion-How being the target of prejudice affects self-control. Psychological Science, 17, 262-269.

Keltner, D., Gruenfeld, D. H., \& Anderson, C. (2003). Power, approach, and inhibition. Psychological Review, 110, 265-284.

Krull, J. L., \& MacKinnon, D. P. (2001). Multilevel modeling of individual and group level mediated effects. Multivariate Behavioral Research, 36, 249-277.

Lazarus, R. S., \& Folkman, S. (1984). Stress, appraisal, and coping. New York, NY: Springer.

Littell, R. C. (2006). SAS for mixed models (2nd ed.). Cary, NC: SAS Institute.

Magee, J. C., Galinsky, A. D., \& Gruenfeld, D. H. (2007). Power, propensity to negotiate, and moving first in competitive interactions. Personality and Social Psychology Bulletin, 33, 200-212.
Major, B. (2006). New perspectives on stigma and psychological well-being. In S. Levin \& C. van Laar (Eds.), Stigma and group inequality: Social psychological perspectives (pp. 193-210). Mahwah, NJ: Erlbaum.

Major, B., Quinton, W. J., \& Schmader, T. (2003). Attributions to discrimination and self-esteem: Impact of social identification and group ambiguity. Journal of Experimental Social Psychology, 39, 220-231.

McCoy, S. K., \& Major, B. (2003). Group identification moderates emotional responses to perceived prejudice. Personality and Social Psychology Bulletin, 29, 1005-1017.

Mendoza-Denton, R., Downey, G., Purdie, V. J., Davis, A., \& Pietrzak, J. (2002). Sensitivity to status-based rejection: Implications for African American students' college experience. Journal of Personality and Social Psychology, 83, 896-918.

Miller, C. T. (2006). Social psychological perspectives on coping with stressors related to stigma. In S. Levin \& C. van Laar (Eds.), Stigma and group inequality: Social psychological perspectives (pp. 21-44). Mahwah, NJ: Erlbaum.

Pinel, E. C. (1999). Stigma consciousness: The psychological legacy of social stereotypes. Journal of Personality and Social Psychology, 76, 114-128.

Quinn, D. M. (2006). Concealable versus conspicuous stigmatized identities. In S. Levin \& C. van Laar (Eds.), Stigma and group inequality: Social psychological perspectives (pp. 45-64). Mahwah, NJ: Erlbaum.

Raudenbush, S. W., \& Bryk, A. S. (2002). Hierarchical linear models: Applications and data analysis methods (2nd ed.). Thousand Oaks, CA: Sage.

Raudenbush, S. W., Bryk, A. S., Cheong, Y. K., \& Congdon, R. T. (2004). HLM 6: Hierarchical linear and nonlinear modeling. Lincolnwood, IL: Scientific Software International.

Raven, B. H. (1993). The bases of power: Origins and recent developments. Journal of Social Issues, 49, 227-251.

Reis, H. T., \& Gable, S. L. (2000). Event-sampling and other methods for studying everyday experience. In H. T. Reis \& C. M. Judd (Eds.), Handbook of research methods in social and personality psychology (pp. 190-222). New York, NY: Cambridge University Press.

Richeson, J. A., \& Shelton, J. N. (2007). Negotiating interracial interactions: Costs, consequences, and possibilities. Current Directions in Psychological Science, 16, 316.

Robins, R. W., Hendin, H. M., \& Trzesniewski, K. H. (2001). Measuring global self-esteem: Construct validation of a single-item measure and the Rosenberg Self-Esteem Scale. Personality and Social Psychology Bulletin, 27, 151-161.

Rosnow, R. L., \& Rosenthal, R. (1996). Computing contrasts, effect sizes, and counternulls on other people's published data: General procedures for research consumers. Psychological Methods, 1, 331-340.

Schaalje, G. B., McBride, J. B., \& Fellingham, G. W. (2001, April). Approximations to distributions of test statistics in complex mixed linear models using SAS Proc MIXED (Paper 262-26). Paper presented at the annual SAS Users Group international conference, Long Beach, CA. 
Schafer, J. L. (1999). NORM: Multiple imputation of incomplete multivariate data under a normal model [Computer software]. University Park: Pennsylvania State University, Department of Statistics.

Schmader, T., \& Johns, M. (2003). Converging evidence that stereotype threat reduces working memory capacity. Journal of Personality and Social Psychology, 85, 440-452.

Sellers, R. M., Rowley, S. A., Chavous, T. M., Shelton, J., \& Smith, M. A. (1997). Multidimensional Inventory of Black Identity: A preliminary investigation of reliability and constuct validity. Journal of Personality and Social Psychology, 73, 805-815.

Sellers, R. M., \& Shelton, J. (2003). The role of racial identity in perceived racial discrimination. Journal of Personality and Social Psychology, 84, 1079-1092.

Sellers, R. M., Smith, M. A., Shelton, J. N., Rowley, S. A. J., \& Chavous, T. M. (1998). Multidimensional Model of Racial Identity: A reconceptualization of African American racial identity. Personality and Social Psychology Review, 2, 18-39.

Shelton, J. N., Richeson, J. A., \& Salvatore, J. (2005). Expecting to be the target of prejudice: Implications for interethnic interactions. Personality and Social Psychology Bulletin, 31, 1189-1202.

Shrout, P. E., \& Fleiss, J. L. (1979). Intraclass correlations: Uses in assessing rater reliability. Psychological Bulletin, 86, 420-428.

Smart, L., \& Wegner, D. M. (2000). The hidden costs of hidden stigma. In T. F. Heatherton, R. E. Kleck, M. R. Hebl, \& J. G. Hull
(Eds.), The social psychology of stigma (pp. 220-242). New York, NY: Guilford.

Smith, P. K., \& Bargh, J. A. (2008). Nonconscious effects of power on basic approach and avoidance tendencies. Social Cognition, 26, 1-24.

Smith, P. K., Jostmann, N. B., Galinsky, A. D., \& van Dijjk, W. W. (2008). Lacking power impairs executive functions. Psychological Science, 19, 441-447.

Sobel, M. E. (1982). Asymptotic intervals for indirect effects in structural equations models. In S. Leinhart (Ed.), Sociological methodology (pp. 290-312). San Francisco, CA: Jossey-Bass.

Steele, C. M., Spencer, S. J., \& Aronson, J. (2002). Contending with group image: The psychology of stereotype and social identity threat. In M. P. Zanna (Ed.), Advances in experimental social psychology (Vol. 34, pp. 379-440). San Diego, CA: Academic Press.

Swim, J. K., \& Thomas, M. A. (2006). Responding to everyday discrimination: A synthesis of research on goal-directed, selfregulatory coping behaviors. In S. Levin \& C. van Laar (Eds.), Stigma and group inequality: Social psychological perspectives (pp. 105-126). Mahwah, NJ: Erlbaum.

Vorauer, J. D., Main, K. J., \& O’Connell, G. B. (1998). How do individuals expect to be viewed by members of lower status groups? Content and implications of meta-stereotypes. Journal of Personality and Social Psychology, 75, 917-937.

Whitley, B. E. (2001). Gender-role variables and attitudes toward homosexuality. Sex Roles, 45, 691-721. 